\title{
Article \\ The Kinetics of Phase Transition of Austenite to Ferrite in Medium-Carbon Microalloy Steel
}

\author{
Liushun Wu, Kunlong Liu (D) and Yun Zhou * \\ School of Metallurgical Engineering, Anhui University of Technology, Ma'anshan 243002, China; \\ wuliushun@ahut.edu.cn (L.W.); ahutlkl@ahut.edu.cn (K.L.) \\ * Correspondence: zhouyunah@ahut.edu.cn; Tel.: +86-13955585501
}

Citation: Wu, L.; Liu, K.; Zhou, Y. The Kinetics of Phase Transition of Austenite to Ferrite in MediumCarbon Microalloy Steel. Metals 2021, 11, 1986. https://doi.org/10.3390/ met11121986

Academic Editor: Marcello Cabibbo

Received: 27 October 2021

Accepted: 6 December 2021

Published: 9 December 2021

Publisher's Note: MDPI stays neutral with regard to jurisdictional claims in published maps and institutional affiliations.

Copyright: (c) 2021 by the authors. Licensee MDPI, Basel, Switzerland. This article is an open access article distributed under the terms and conditions of the Creative Commons Attribution (CC BY) license (https:/ / creativecommons.org/licenses/by/ $4.0 /)$.

\begin{abstract}
To reduce energy and resource consumption, high-strength hot-rolled rebars with yield strengths of $\geq 400 \mathrm{MPa}$ (HRB500) and $\geq 500 \mathrm{MPa}$ (HRB600) have been designed and produced in recent years. Optimizing the microstructure in the steel to improve strength necessitates determining the kinetics of the phase transition of austenite to polygonal ferrite. Therefore, in the study, the effect of temperature and holding time on the volume fraction of ferrite is investigated in HRB500 and HRB600 steels. Experimental results show that the ferrite percentage initially increases with an increase in temperature and then decreases as the temperature increases from 600 to $730{ }^{\circ} \mathrm{C}$. The optimum temperature range is $680-700{ }^{\circ} \mathrm{C}$ for HRB500 steel and $650-680{ }^{\circ} \mathrm{C}$ for HRB600 steel. Based on the Johnson-Mehl-Avrami equation, phase transition kinetic models are established. Model predictions are consistent with the validation data. Thus, this study establishes a reference for studying ferrite formation during cooling.
\end{abstract}

Keywords: austenite; ferrite; phase transition; kinetics; hot-rolled ribbed steel bars

\section{Introduction}

In recent years, to reduce energy and resource consumption, high-strength hot-rolled rebars, namely HRB500 (yield strength of $\geq 400 \mathrm{MP}$ ) and HRB600 (yield strength of $\geq 500 \mathrm{MPa}$ ), have been developed [1,2] that will substitute for low-grade rebars, such as HRB335. In production, the contemporary method involves microalloying during smelting, rolling 12-18 times (primary rolling: 5-6 times, at 20-30\% strain, with about $20 \mathrm{~S}^{-1}$ strain rate; middle rolling: similar to primary rolling; finishing rolling: $5-7$ times, at $10-20 \%$ strain, with about $100 \mathrm{~S}^{-1}$ strain rate) at a temperature of $950{ }^{\circ} \mathrm{C}$ to $850{ }^{\circ} \mathrm{C}$, cooling to $600-650{ }^{\circ} \mathrm{C}$, followed by cooling in a cooling bed. The processes of microalloying and rolling are standardized, while the controlled cooling may be further optimized.

During cooling, the transformation from austenite to ferrite in steel is very important because the morphology and volume fraction of ferrite in steels significantly impact its mechanical properties [3,4]. Thus, it is necessary to clearly understand the mechanism of transformation from austenite to ferrite during cooling, i.e., nucleation, thermodynamics, and kinetics.

The nucleation of ferrite in Fe-X-Y systems ( $X$ represents substitutional elements such as $\mathrm{Mn}, \mathrm{Si}, \mathrm{Ni}, \mathrm{Cr}, \mathrm{Mo}, \mathrm{Co}, \mathrm{V}, \mathrm{Ti}$, and $\mathrm{Nb}$, and $\mathrm{Y}$ represents interstitial elements, such as $\mathrm{C}$ and $\mathrm{N}$ ) has been studied extensively [5], and the investigations have demonstrated that interface character [6,7], carbides [8], austenite grain size [9,10], and compressive stress [11,12] influence ferrite formation.

For the thermodynamic mechanism of ferrite formation, the local equilibrium and the quasi-equilibrium theories [13-15] are currently used to describe Fe-C-X systems. In the local equilibrium theory, ferrite transition is classified into two types. At a relatively high temperature, the alloy elements are redistributed between austenite and ferrite during the formation of ferrite. In this case, the formation of ferrite is controlled by the diffusion of alloy elements, resulting in the slow growth of ferrite, which is called the 
distribution local equilibrium mode. At lower temperatures, the alloy elements are only slightly redistributed during the formation of ferrite, and the diffusion of $C$ determines the formation of ferrite, which is referred to as the non-distribution local equilibrium mode. In the quasi-equilibrium theory, assuming that only $\mathrm{C}$ reaches a complete local equilibrium at the interface between austenite and ferrite, alloy elements do not undergo redistribution during transformation. Based on these theories, specific models were developed, including the cellular automata model $[16,17]$, the mixed-mode multigrain model [18], and the numerical model $[19,20]$.

As for the kinetics of phase transition, several methodologies were proposed, such as phase-field [21-23] framework [24] and internal-state variable models [25,26], the Gibbs energy balance model $[27,28]$, the mixed-mode model [29,30], and the Johnson-MehlAvrami equation [31]. These methods were applied to medium and high-alloy steel [32] and low-carbon steel [33-35]. For example, for medium-carbon microalloy steel, such as high-strength hot-rolled rebar, few experimental studies have focused on the transition kinetics of austenite to ferrite. Compared to general-carbon steel, higher requirements in the microstructure are brought forward to improve the strength of medium-carbon microalloy steel. Thus, it is necessary to investigate the formation kinetics of ferrite in medium-carbon microalloy steel. Accordingly, in this study, taking hot-rolled ribbed steel (HRB500 and HRB600 grade steels) as an example, we investigate the kinetics of ferrite formation in medium-carbon microalloy steel by controlling the cooling process and developing kinetics equations based on the Johnson-Mehl-Avrami equation. This study provides significant insights into controlling the structure and performance of products and designing an appropriate rolling, cooling, and heat-treatment process.

\section{Materials and Methods}

Hot-rolled ribbed steel bars HRB500 and HRB600 were selected for this study; their chemical compositions are listed in Table 1 . The samples were heated to $950{ }^{\circ} \mathrm{C}$ for austenitization in a box-type resistance furnace (TCW-32B, Changsha Kexin Co., Ltd., Changsha, China) and then cooled using different cooling methods (in a furnace, air, and water). A K-type thermocouple was welded at the center of the sample using a spot welder (PW1200ST, Zhenjiang Jinggong Welding Equipment Co., Ltd., Zhengjiang, China), and it was then connected to a high-speed data acquisition card (Ni-Daq680-1, National Instruments Co., Ltd., Austin, TX, USA). Time data corresponding to voltage were collected using this card. The relationship between time and voltage was presented as a function of time and temperature. Based on the curve of cooling time versus temperature, cooling rates corresponding to different cooling methods were determined.

Table 1. Chemical composition of HRB500 and HRB600 hot-rolled ribbed steel bars.

\begin{tabular}{ccccccc}
\hline Grade & C & Si & Mn & P & S & V \\
\hline HRB500 & 0.25 & 0.63 & 1.53 & 0.025 & 0.018 & 0.056 \\
HRB600 & 0.26 & 0.68 & 1.47 & 0.023 & 0.021 & 0.168 \\
\hline
\end{tabular}

A continuous-cooling transformation diagram was produced using JMatPro material performance simulation software (Sente Software Ltd., Guildford, UK). The temperature range of ferrite formation was determined using this diagram. It provided a basis for the selection of temperature ranges in the subsequent study of the kinetics of ferrite formation.

To determine an accurate phase-transition temperature, the Gleeble thermal simulation was carried out. Using the Gleeble $\mathrm{T}^{(\mathrm{TM})}$ thermal simulator (Gleeble-3500, Data Sciences International, Inc., St. Paul, MN, USA) the samples were heated to $1100{ }^{\circ} \mathrm{C}$ and kept for several minutes at this temperature. The temperature was then reduced to $950{ }^{\circ} \mathrm{C}$ and held for several minutes. After that, the sample was compressed to deform, the temperature was reduced to $850{ }^{\circ} \mathrm{C}$, and the sample was then cooled to room temperature at a selected cooling rate (corresponding to the cooling rate in furnace) to obtain the curve of the temper- 
ature versus the size. The phase transition temperature was determined by the inflection point of the thermal expansion curve (Tangent method, see Supplementary Materials).

The steel bars were cut into cylinders $(\varphi 22 \mathrm{~mm} \times 15 \mathrm{~mm})$ using the wire-cutting technique. The cylinder samples were heated to the austenitizing temperature of $950{ }^{\circ} \mathrm{C}$ in the resistance furnace, and the temperature was maintained for $15 \mathrm{~min}$. The samples were then cooled to a predetermined temperature (about $5{ }^{\circ} \mathrm{C} / \mathrm{S}$ ). The holding time was $1,3,5,8,11$, and 15 min at predetermined temperatures, respectively. Finally, the samples were cooled to room temperature in water.

The cooled samples were ground and polished, eroded with $4 \%$ nitric acid, and finally, cleaned with water and alcohol and dried. The treated samples were observed using a metallographic microscope (OLYMPUS-BX51, Olympus Corporation, Tokyo, Japan). The images were captured at a magnification of $200 \times$ and $500 \times$.

The images display different phases in different colors. Generally, ferrite is brightgreen. ImagePro-Plus software was used to identify and calibrate different colors and to calculate the pixel of ferrite. The volume fraction of ferrite was obtained by converting the ratio of the pixel of the phase to that of the whole picture. To ensure the accuracy of the phase volume fraction, five different fields of view were selected in the center of each sample. Each photo was treated three times using the software, and the average value of the pixel was obtained. The number and size of ferrite were obtained using Nano Measure software (Microsoft, Redmond, Washington, DC, USA).

\section{Results}

Figure 1 shows the microstructure of the samples cooled in the furnace, air, and water. As the cooling rate increases, the percentage of ferrite in the samples decreases. As observed in Figure 1, when the cooling rate is very low (Figure 1a), the microstructure is mainly ferrite and pearlite; when the cooling rate is fast (Figure 1c), the microstructure is mainly martensite.
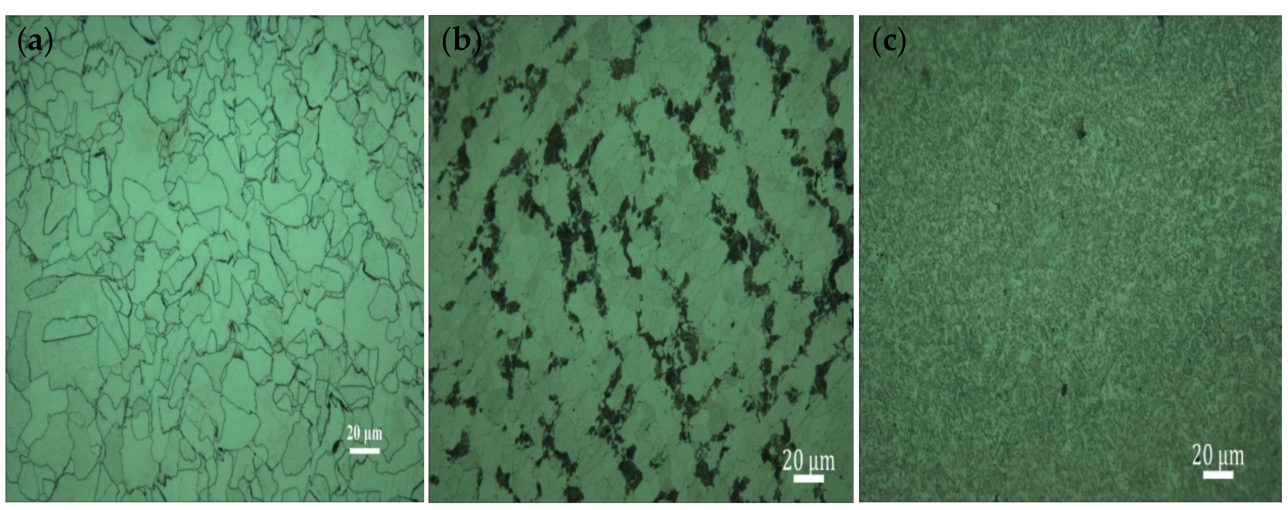

Figure 1. Microstructure images of the samples cooled in furnace (a), air (b) and water (c).

The continuous cooling transformation (CCT) diagram (see Figure 2) also shows that when the cooling rate is below $2{ }^{\circ} \mathrm{C} / \mathrm{s}$, a small amount of pearlite is formed, and the microstructure is mainly ferrite [36]. Thus, the subsequent cooling experiment was carried out by cooling in the furnace. The experimental results agree with the Jmatpro prediction.

The results of the Gleeble thermal simulation show that the temperature for the formation of ferrite is between $625^{\circ} \mathrm{C}$ and $736{ }^{\circ} \mathrm{C}$, and the formation time is approximately $16.67 \mathrm{~min}$. Thus, in the subsequent experiment, the temperature range of $600-730{ }^{\circ} \mathrm{C}$ is selected. 


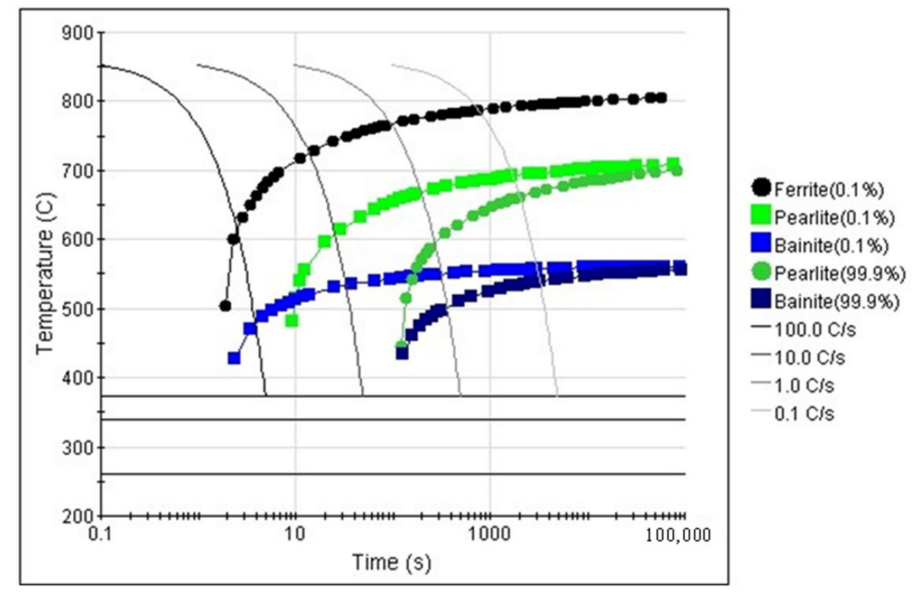

Figure 2. Continuous cooling transformation (CCT) diagram of HRB500.

Figures 3 and 4 show the microstructures of the HRB500 and HRB600 grade steel samples, respectively, when they were held for $11 \mathrm{~min}$ at different temperatures. The samples comprised bright-green polygonal ferrite and pearlite phases. With an increase in temperature, the volume fraction of ferrite initially increases and then decreases. For the HRB500 steel samples held at $680-700{ }^{\circ} \mathrm{C}$, the volume fractions of ferrite exceed $50 \%$, which is higher than that of the samples held at other temperatures. For the HRB600 steel samples held at $650-680^{\circ} \mathrm{C}$, the volume fraction of ferrite is $>50 \%$, which is higher than that of the samples held at other temperatures. This indicates that the optimal temperature range for ferrite formation in HRB500 and HRB600 steels is $680-700{ }^{\circ} \mathrm{C}$ and $650-680{ }^{\circ} \mathrm{C}$, respectively.
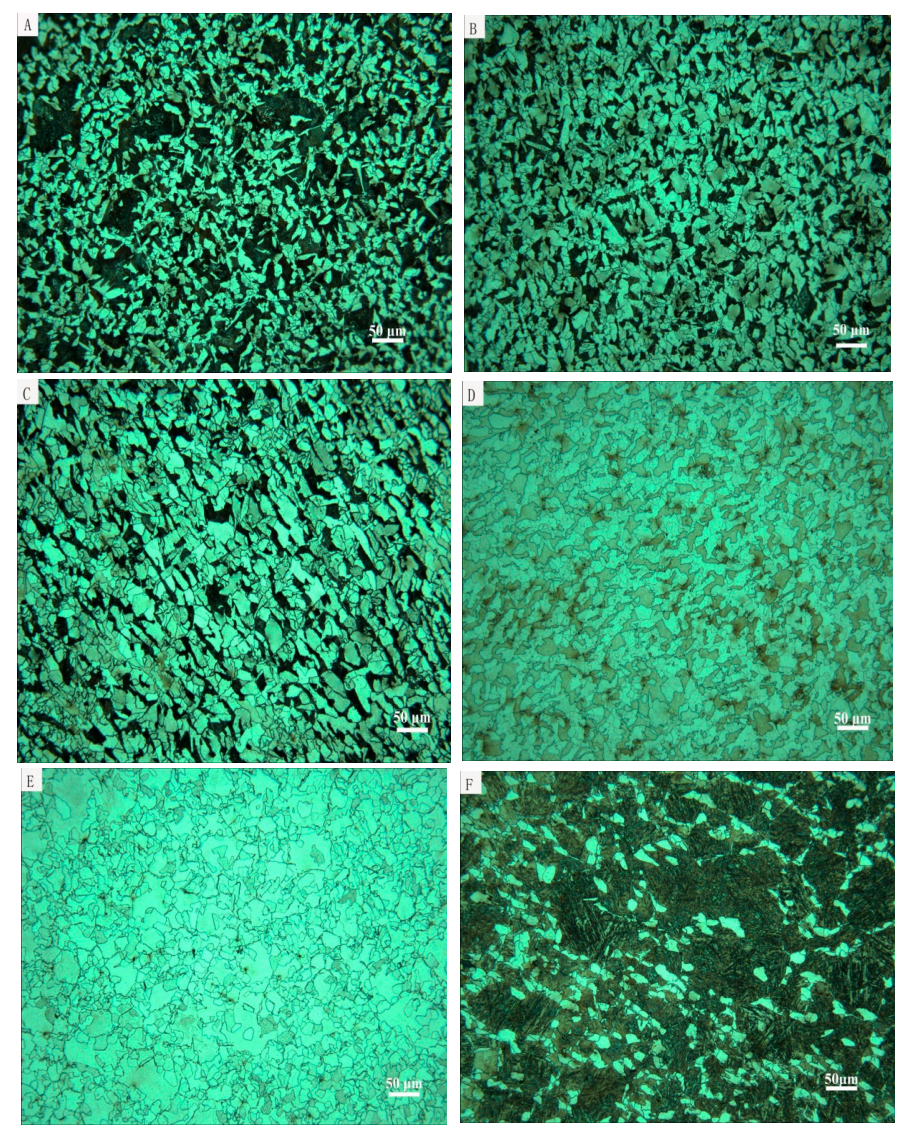

Figure 3. Microstructures of HRB500 steel samples with a holding time of $11 \mathrm{~min}$ at different temperatures (A): $600{ }^{\circ} \mathrm{C},(\mathbf{B}): 630{ }^{\circ} \mathrm{C},(\mathbf{C}): 650{ }^{\circ} \mathrm{C},(\mathbf{D}): 680{ }^{\circ} \mathrm{C},(\mathrm{E}): 700{ }^{\circ} \mathrm{C},(\mathrm{F}): 730{ }^{\circ} \mathrm{C}$. 

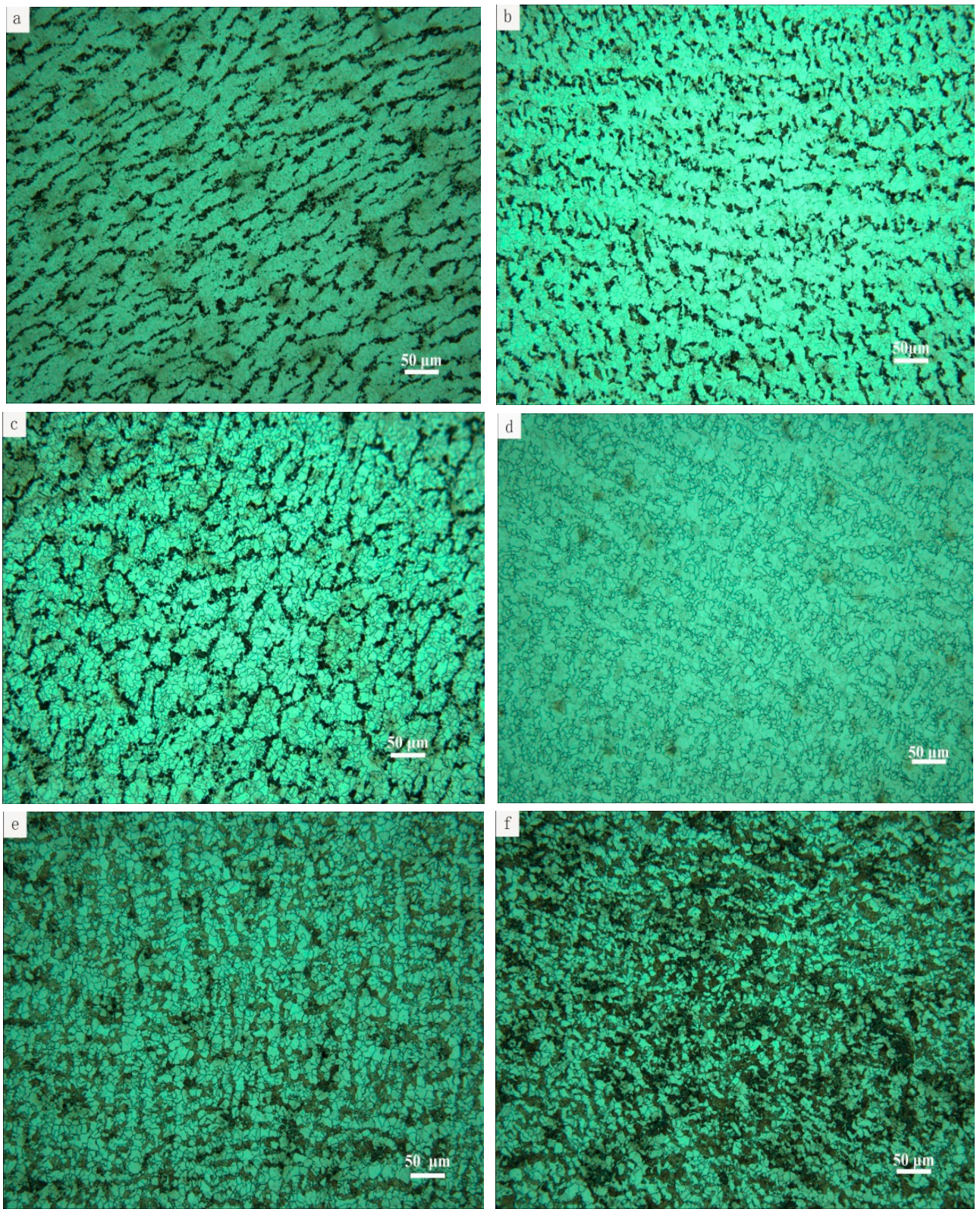

Figure 4. Microstructures of HRB600 grade steel samples with a holding time of 11 min at different temperatures (a): $600{ }^{\circ} \mathrm{C},(\mathbf{b}): 630{ }^{\circ} \mathrm{C},(\mathbf{c}): 650{ }^{\circ} \mathrm{C},(\mathbf{d}): 680{ }^{\circ} \mathrm{C},(\mathbf{e}): 700{ }^{\circ} \mathrm{C},(\mathbf{f}): 730{ }^{\circ} \mathrm{C}$.

The average grain sizes of ferrite in the samples are listed in Table 2. For HRB500 steel, with increasing temperature, the grain size of ferrite first increases and then decreases. Except for a few samples, most of the samples show relatively few differences in the grain size of ferrite with increasing duration. For HRB600 steel, with an increase in temperature from $600{ }^{\circ} \mathrm{C}$ to $700{ }^{\circ} \mathrm{C}$, the grain size of ferrite shows little variation, while the samples quenched at $730^{\circ} \mathrm{C}$ show a much bigger ferrite grain size than those quenched at other temperatures. The increase in the average grain size may indicate that growth contributes more to the overall transformation than nucleation, to some extent. Relatively, in HRB500 steel, the growth is attributed more to the transformation from austenite to ferrite than that of HRB600. 
Table 2. Grain sizes of ferrite in the samples held at different temperatures for different durations (diameter, $\mu \mathrm{m})$.

\begin{tabular}{|c|c|c|c|c|c|c|c|}
\hline Grade & Temperature $\left({ }^{\circ} \mathrm{C}\right)$ & $1 \mathrm{~min}$ & $3 \mathrm{~min}$ & $5 \mathrm{~min}$ & $8 \mathrm{~min}$ & $11 \mathrm{~min}$ & $15 \mathrm{~min}$ \\
\hline \multirow{6}{*}{ HRB500 } & 600 & 7.7 & 10.0 & 11.4 & 11.2 & 12.0 & 12.4 \\
\hline & 630 & 12.5 & 13.0 & 12.8 & 15.3 & 16.8 & 14.4 \\
\hline & 650 & 13.1 & 13.7 & 14.2 & 16.2 & 13.4 & 13.4 \\
\hline & 680 & 15.2 & 11.7 & 13.3 & 12.0 & 12.8 & 16.1 \\
\hline & 700 & 13.3 & 14.2 & 15.5 & 12.5 & 14.0 & 17.9 \\
\hline & 730 & 13.8 & 12.7 & 13.8 & 11.2 & 11.3 & 13.6 \\
\hline \multirow{6}{*}{ HRB600 } & 600 & 9.5 & 8.8 & 8.4 & 7.7 & 7.3 & 9.1 \\
\hline & 630 & 9.3 & 9.1 & 10.9 & 9.4 & 8.9 & 8.6 \\
\hline & 650 & 7.5 & 8.1 & 8.6 & 8.2 & 7.3 & 9.2 \\
\hline & 680 & 8.1 & 8.3 & 9.0 & 9.4 & 8.5 & 9.2 \\
\hline & 700 & 9.3 & 9.0 & 8.7 & 9.7 & 9.5 & 9.2 \\
\hline & 730 & 10.9 & 9.7 & 11.7 & 12.8 & 12.1 & 13.6 \\
\hline
\end{tabular}

Table 3. The number of grains of ferrite in unit area $(100 \mu \mathrm{m} \times 100 \mu \mathrm{m})$.

\begin{tabular}{|c|c|c|c|c|c|c|c|}
\hline Grade & Temperature $\left({ }^{\circ} \mathrm{C}\right)$ & $1 \mathrm{~min}$ & $3 \mathrm{~min}$ & $5 \mathrm{~min}$ & $8 \mathrm{~min}$ & $11 \mathrm{~min}$ & $15 \mathrm{~min}$ \\
\hline \multirow{6}{*}{ HRB500 } & 600 & 67 & 56 & 62 & 75 & 51 & 58 \\
\hline & 630 & 57 & 65 & 64 & 63 & 41 & 52 \\
\hline & 650 & 55 & 57 & 67 & 41 & 33 & 37 \\
\hline & 680 & 37 & 41 & 41 & 56 & 48 & 38 \\
\hline & 700 & 37 & 35 & 43 & 25 & 24 & 23 \\
\hline & 730 & 20 & 19 & 28 & 26 & 27 & 26 \\
\hline \multirow{6}{*}{ HRB600 } & 600 & 102 & 110 & 141 & 141 & 139 & 172 \\
\hline & 630 & 135 & 145 & 136 & 148 & 147 & 163 \\
\hline & 650 & 212 & 153 & 167 & 146 & 131 & 133 \\
\hline & 680 & 196 & 121 & 103 & 106 & 110 & 111 \\
\hline & 700 & 95 & 128 & 128 & 117 & 112 & 126 \\
\hline & 730 & 92 & 102 & 89 & 41 & 57 & 64 \\
\hline
\end{tabular}

Table 4 shows the volume fraction of ferrite in the samples held at different temperatures for different durations. At the same temperature, with a longer holding time, the volume fraction of ferrite increases, and under the same holding time, with an increase in temperature, the volume fraction of ferrite initially increases and then decreases, generally reaching the maximum at $650{ }^{\circ} \mathrm{C}$.

Table 4. Volume percentage of ferrite in the samples held at different temperatures for different durations.

\begin{tabular}{|c|c|c|c|c|c|c|c|}
\hline Grade & Temperature $\left({ }^{\circ} \mathrm{C}\right)$ & $1 \mathrm{~min}$ & $3 \mathrm{~min}$ & $5 \mathrm{~min}$ & $8 \mathrm{~min}$ & $11 \mathrm{~min}$ & $15 \mathrm{~min}$ \\
\hline \multirow{6}{*}{ HRB500 } & 600 & 1.5 & 5.6 & 9.6 & 15.5 & 31.2 & 59.7 \\
\hline & 630 & 3.8 & 10.2 & 19.8 & 32.6 & 57.3 & 89.5 \\
\hline & 650 & 3.2 & 15.9 & 28.2 & 46.3 & 60.2 & 75.1 \\
\hline & 680 & 2.9 & 9.3 & 18.2 & 30.4 & 55.7 & 85.2 \\
\hline & 700 & 2.7 & 5.3 & 8.2 & 13.7 & 31.1 & 55.9 \\
\hline & 730 & 0.8 & 3.7 & 6.9 & 12.4 & 22.3 & 42.1 \\
\hline \multirow{6}{*}{ HRB600 } & 600 & 2.3 & 20.3 & 42.8 & 61.7 & 77.1 & 87.5 \\
\hline & 630 & 4.8 & 19.6 & 38.6 & 59.4 & 79.5 & 87.3 \\
\hline & 650 & 8.5 & 21.8 & 43.9 & 66.2 & 86.7 & 98.2 \\
\hline & 680 & 8.1 & 22.8 & 43.9 & 64.3 & 89.7 & 97.1 \\
\hline & 700 & 6.1 & 15.4 & 29.8 & 43.8 & 62.6 & 89.8 \\
\hline & 730 & 2.6 & 13.3 & 24.1 & 38.6 & 59.5 & 83.2 \\
\hline
\end{tabular}

The experimental results show that the combined impact of holding temperature and holding time influences the formation of ferrite in the HRB500 and HRB600 steel samples. 


\section{Discussion}

\subsection{Nucleation and Growth of Ferrite}

According to experimental results, with increasing temperature and duration, ferrite's average grain size and grain number show obvious changes, especially for HRB600 steel. The results indicate that the generation of new nuclei and grain impinging occur during cooling. Growth and grain impinging cause the development of larger ferrite grains.

\subsection{Phase Transition Kinetic Model}

Typically, quasi-polygonal ferrite and granular ferrite are formed in the temperature range of $500-700{ }^{\circ} \mathrm{C}$, where $\mathrm{Fe}$ and alloy elements can still undergo short-range diffusion, while $\mathrm{C}$ atoms can also undergo long-range diffusion. This activity of atoms determines the type of ferrite formed. In addition, with the increase in the ferrite volume fraction, the carbon content of austenite gradually increases, and pearlite starts to generate. This influences the formation of ferrite, especially at lower temperatures. Here, the Avrami empirical equation is used to process the experimental data.

According to the empirical equation proposed by Avrami, the volume fraction F of ferrite can be expressed as shown in Equation (1) [37]

$$
\mathrm{F}=1-\exp \left(-\mathrm{Kt}^{\mathrm{n}}\right)
$$

where $\mathrm{F}$ is the phase transition in time $\mathrm{t}, \mathrm{K}$ is a function of the phase transition temperature, and $\mathrm{n}$ is a constant.

By rearranging Equation (1) and taking the logarithm on both sides, Equation (2) is obtained.

$$
\ln \ln [1 /(1-\mathrm{F})]=\ln \mathrm{K}+\mathrm{nln} \mathrm{t}
$$

In Equation (4), $\ln \ln [1 /(1-F)]$ and $\operatorname{lnt}$ are considered as $\mathrm{Y}$ and $\mathrm{X}$ of linear function, and $\mathrm{n}$ and $\operatorname{lnK}$ are the slope and the intercept, respectively.

According to the literature [38,39], the value of $\mathrm{n}$ depends on the type of nucleation. $\mathrm{K}$ is related to the phase transformation mechanism, isothermal temperature (T), and the shape of the isothermal transformation curve. The relationship between $\mathrm{K}$ and $\mathrm{T}$ can be expressed by the modified Gaussian function [40,41], as shown in Equation (3).

$$
\mathrm{K}=\mathrm{a} \cdot \exp \left\{-[(\mathrm{T}-\mathrm{b}) / \mathrm{c}]^{\mathrm{d}}\right\}
$$

Taking the logarithm on both sides of Equation (4), Equation (4) is obtained.

$$
\operatorname{lnK}=\ln \mathrm{a}-[(\mathrm{T}-\mathrm{b}) / \mathrm{c}]^{\mathrm{d}}
$$

In Equation (4), the four parameters, a, b, c, and d, are related to the shape of time, temperature, and transformation diagrams; $a$ is the maximum value of $\mathrm{K}, \mathrm{b}$ is the corresponding temperature at the nose point of the curve, $\mathrm{c}$ is the standard mean square error, and $d$ is a constant related to the curvature of the curve.

As shown in Equation (4), the relationship between $\ln \mathrm{K}$ and the temperature $\mathrm{T}$ fits well in the d-order function. According to a previous study [42], lnK and t conform to the quadratic function, i.e., $\mathrm{d}=2$. In this study, $\mathrm{d}$ was considered 2 .

\subsection{Kinetics of Ferrite Formation in HRB500 Steel}

By substituting the volume fractions of ferrite into $\ln \ln [1 /(1-F)]$, and taking the $\operatorname{logarithm}(\operatorname{lnt})$, two sets of data are obtained, which can be regarded as $\mathrm{Y}$ and $\mathrm{X}$, respectively. The values of $\operatorname{lnK}$ and $\mathrm{n}$ are obtained by linear fitting. Table 5 lists the values of $\operatorname{lnK}$ and $\mathrm{n}$ at different temperatures. By taking an average of the values of $n$, a value of 1.43 is obtained. By substituting the value of $\mathrm{n}$ in Equation (1), we obtain

$$
\mathrm{F}=1-\exp \left(-\mathrm{Kt}^{1.43}\right)
$$


Table 5. $\mathrm{n}$ and $\operatorname{lnK}$ values obtained from linear fitting.

\begin{tabular}{cccc}
\hline Temperature $/{ }^{\circ} \mathbf{C}$ & $\mathbf{n}$ & $\operatorname{lnK}$ & R-Square \\
\hline 600 & 1.42464 & -4.38239 & 0.95231 \\
630 & 1.42827 & -3.56681 & 0.93068 \\
650 & 1.37801 & -3.35750 & 0.99770 \\
680 & 1.48263 & -3.78316 & 0.95392 \\
700 & 1.38380 & -4.29457 & 0.86418 \\
730 & 1.49667 & -4.92518 & 0.98400 \\
\hline
\end{tabular}

By fitting the relationship between $\mathrm{K}$ and $\mathrm{T}$ using a modified Gaussian function, the values of the parameters of $a, b, c$, and $d$ in the Gaussian function are determined, as shown in Equation (6). The fitting curve is shown in Figure 5, and the coefficient of determination is 0.93925 , which means that the model highly matches experimental results.

$$
\mathrm{K}=0.0332 \cdot \exp \left\{-[(\mathrm{T}-650.88) / 53.1]^{2}\right\}
$$

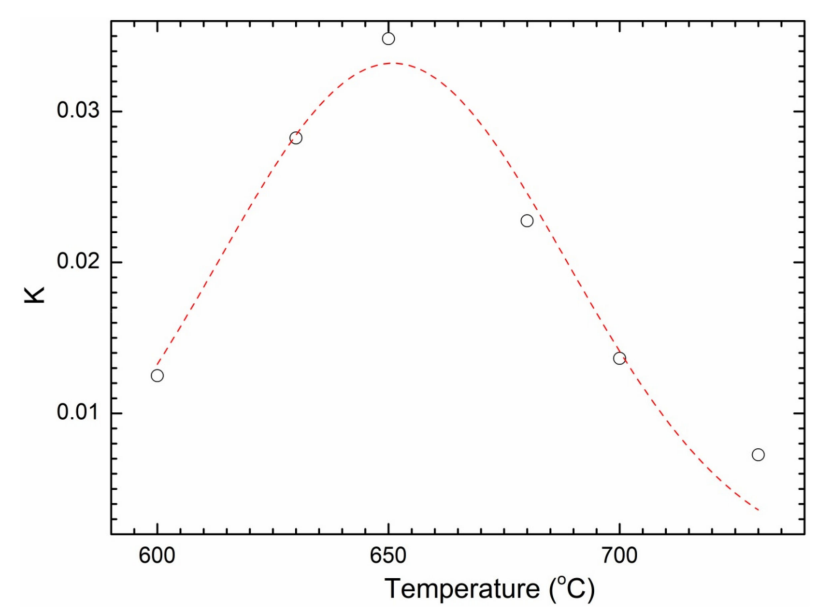

Figure 5. Gaussian fitting of $\mathrm{K}$ to temperature $(\mathrm{T})$.

To verify the accuracy of the model, the samples were held for $1,3,5,8,11$, and 15 min at $690^{\circ} \mathrm{C}$, and then quenched with water each time. The percentage of the volume of ferrite in the samples was compared to the results of the model calculation. As shown in Figure 6, the model predictions are consistent with the experimental results, and the deviation in the predicted value is $<10 \%$.

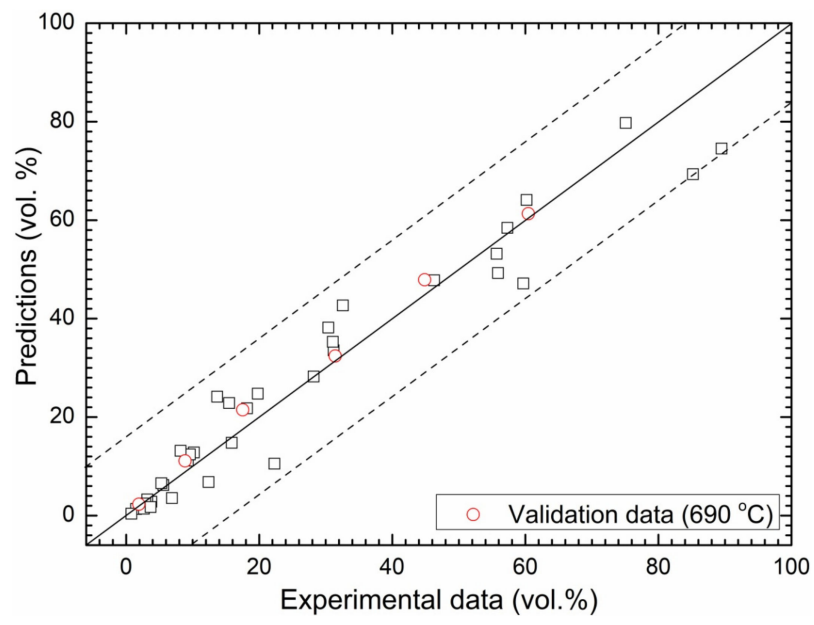

Figure 6. Comparison of predicted and experimental values. 


\subsection{Kinetics of Ferrite Formation in HRB600 Steel}

Even for HRB600 steel samples, the values of $\operatorname{lnK}$ and $n$ were obtained by linear fitting. The values of $\ln K$ and $\mathrm{n}$ at different temperatures are listed in Table 6 . Here, the average value of $n$ is 1.44. By substituting the value of $n$ in Equation (1), we obtain

$$
\mathrm{F}=1-\exp \left[-\mathrm{Kt}^{1.44}\right]
$$

Table 6. Values of $n$ and $\ln K$.

\begin{tabular}{cccc}
\hline Temperature $\left({ }^{\circ} \mathbf{C}\right)$ & $\mathbf{n}$ & $\operatorname{lnK}$ & R-Square \\
\hline 600 & 1.65361 & -3.51784 & 0.97809 \\
630 & 1.41069 & -3.02133 & 0.99752 \\
650 & 1.39411 & -2.66513 & 0.96789 \\
680 & 1.39170 & -2.67084 & 0.97585 \\
700 & 1.26952 & -2.98254 & 0.95657 \\
730 & 1.50195 & -3.66190 & 0.99206 \\
\hline
\end{tabular}

The relationship between $\mathrm{K}$ and $\mathrm{T}$ for HRB600 grade steel was fitted using a modified Gaussian function using the same method as the one used for HRB500 grade steel. The formula with the determined coefficients of a, b, c and d is displayed in Equation (8). The $K$ values and the fitting curve are displayed in Figure 7 . The coefficient of determination is 0.95635 , indicating that the fitting matches experimental results.

$$
\mathrm{K}=0.0711 \cdot \exp \left\{-[(\mathrm{T}-664.49) / 64.75]^{2}\right\}
$$

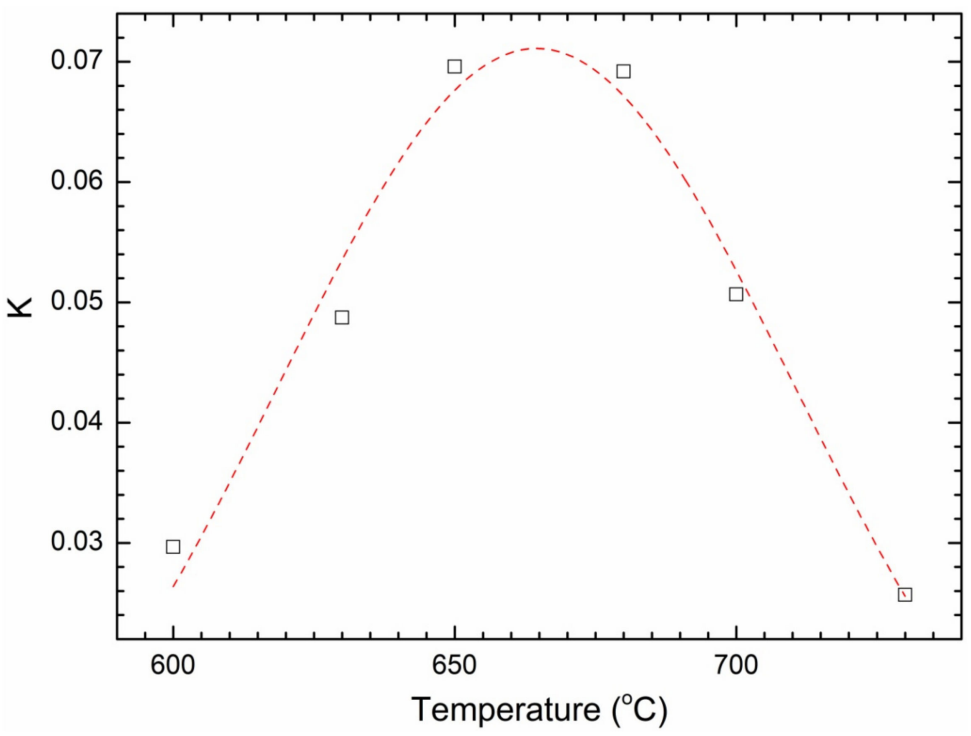

Figure 7. Gaussian Fitting for K to temperature.

To verify the accuracy of the model, the samples were held for 1, 3, 5, 8, 11, and $15 \mathrm{~min}$ at $670{ }^{\circ} \mathrm{C}$, and then quenched with water each time. The comparison of the percentage of the volume of the ferrite in HRB600 steel at $670{ }^{\circ} \mathrm{C}$ to that of the model calculation is shown in Figure 8. Except for a few outliers, the difference between the experimental data and the predicted values is $<10 \%$ (deviation range of $10 \%$ is acceptable in the steelmaking industry), which indicates that the model can play a significant role in predicting ferrite production. 


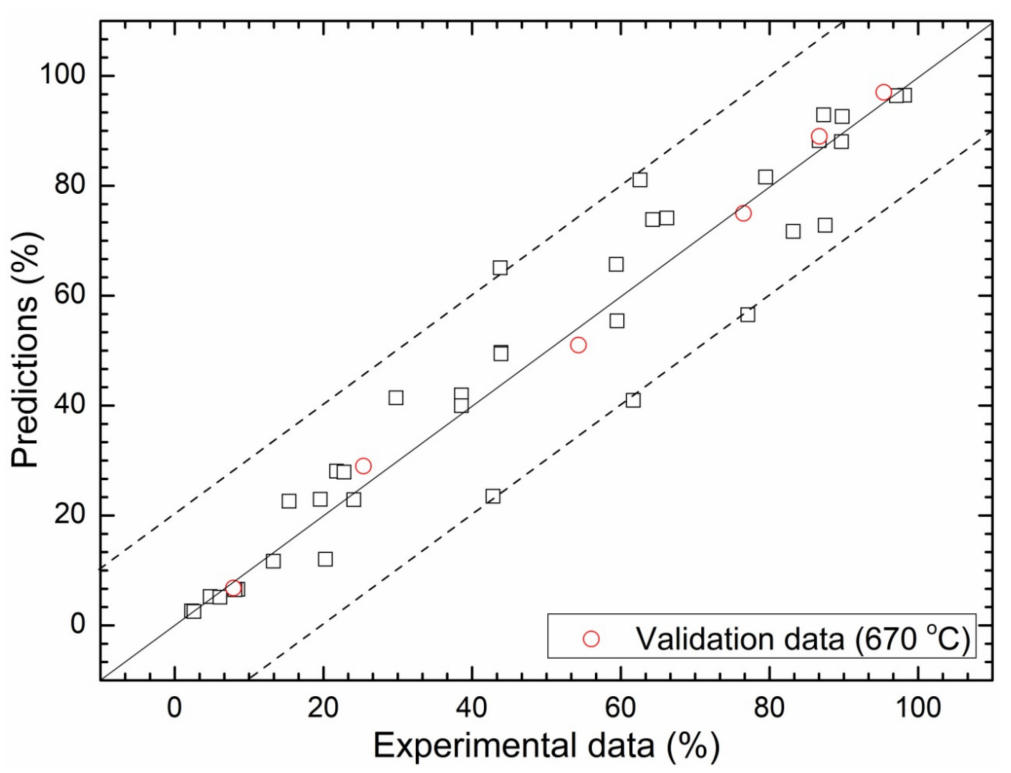

Figure 8. Comparison of predicted and experimental values.

Ferrite exists as a softening phase in steel; it improves the plasticity and toughness of the material but reduces the strength of steel. A large number of studies [43-45] have shown that the volume percentage of ferrite significantly influences the plasticity of steel, while the increase in the volume percentage greatly improves the plasticity of steel. Therefore, in the microstructure design of high-strength rebar, strength, as well as toughness, should be considered, and ferrite should be introduced as a softening phase to enhance toughness.

\section{Conclusions}

The samples were treated by using the isothermal quenching method, and ImageProPlus software was used to determine the ferrite fraction in the steel samples. Based on the results, the kinetics of ferrite formation in HRB500 and HRB600 grade steels was determined. The main findings are summarized as follows.

Based on the cooling curve, microstructure, and CCT curve of the steel samples, the transformation of austenite to ferrite in HRB500 and HRB600 grade steels is the mainphase transition when the cooling rate is $<2{ }^{\circ} \mathrm{C} / \mathrm{s}$. In HRB500 and HRB600 grade steels, the transformation takes place in the temperature range of $600-730{ }^{\circ} \mathrm{C}$. With an increase in temperature, the transformation rate initially increases and then begins to decrease, reaching an optimum value at $680-700{ }^{\circ} \mathrm{C}$ and $650-680^{\circ} \mathrm{C}$ for HRB500 and HRB600 grade steels, respectively. Relatively, the ferrite in HRB600 shows a smaller grain size, possibly owing to a higher vanadium content.

Models for the formation of ferrite in HRB500 and HRB600 grade steels were established based on the Avrami empirical equation; the coefficients of determination were 0.93925 and 0.95635 , respectively. The predictions of the models match the verification tests well, barring a few outliers. It should be noted that the study was carried out without using the forming condition; therefore, the effect of forming and the resulting recrystallization influencing the transformation behavior need to be further investigated.

Supplementary Materials: The following are available online at https:/ /www.mdpi.com/article/10 $.3390 /$ met11121986/s1, Figure S1: Thermal expansion curve of HRB500 steel sample at the cooling rate $0.5^{\circ} \mathrm{C} / \mathrm{s}$ and $1.0^{\circ} \mathrm{C} / \mathrm{s}$, Figure S2: Microstructures of HRB500 grade steel samples with a holding time of 3, 8 and $11 \mathrm{~min}$ at $650^{\circ} \mathrm{C}$, Figure S3: Microstructures of HRB500 grade steel samples with a holding time of 5, 8 and $11 \mathrm{~min}$ at $700{ }^{\circ} \mathrm{C}$, Figure S4: Microstructures of HRB600 grade steel samples with a holding time of 5, 11 and $15 \mathrm{~min}$ at $700{ }^{\circ} \mathrm{C}$, Figure S5: Microstructures of HRB600 grade steel samples with a holding time of 5,8 and $15 \mathrm{~min}$ at $730{ }^{\circ} \mathrm{C}$. 


\begin{abstract}
Author Contributions: L.W.: methodology, validation, formal analysis, investigation, data curation, writing — original draft, visualization, project administration, funding acquisition; K.L.: methodology, validation, formal analysis, investigation, writing - original draft, project administration, investigation; Y.Z.: conceptualization, methodology, validation, formal analysis, resources, data curation, supervision, project administration, writing-review and editing. All authors have read and agreed to the published version of the manuscript.
\end{abstract}

Funding: This research received no external funding.

Conflicts of Interest: The authors declare that there are no conflicts of interest regarding the publication of this paper.

\title{
References
}

1. Xu, Q.; Wang, J.; Ding, Z.; Xia, J.; Rasa, A.R.; Shen, Q. Experimental investigation and analysis on anchorage performance of $635 \mathrm{MPa}$ hot-rolled ribbed high strength rebars. Structures 2021, 30, 574-584. [CrossRef]

2. Sheng, X.-W.; Zheng, W.-Q.; Yang, Y. Tensile and high-cycle fatigue performance of HRB500 high-strength steel rebars joined by flash butt welding. Constr. Build. Mater. 2020, 241, e118037. [CrossRef]

3. Zhang, L.F.; Song, R.B.; Zhao, C.; Yang, F.O.; Xu, Y.; Peng, S.G. Evolution of the microstructure and mechanical properties of an austenite-ferrite Fe-Mn-Al-C steel. Mater. Sci. Eng. A Struct. 2015, 643, 183-193. [CrossRef]

4. Kalantari, A.-R.; Zarei-Hanzaki, A.; Abedi, H.R.; Park, S.-J.; Park, J.Y. Microstructural-constraint induced ferrite refinement during compressive deformation of a triplex ferrite-based low density steel. Vacuum 2021, 193, e110534. [CrossRef]

5. Zhang, J.; Hu, X.; Chou, K. In-situ environmental transmission electron microscopy investigation of the phase transformation austenite $\rightarrow$ ferrite in duplex stainless steel. Mater. Lett. 2020, 264, e127259. [CrossRef]

6. Dong, H.K.; Zhang, Y.J.; Miyamoto, G.; Chen, H.; Yang, Z.G.; Furuhara, T. A comparative study on intrinsic mobility of incoherent and semicoherent interfaces during the austenite to ferrite transformation. Scr. Mater. 2020, 188, 59-63. [CrossRef]

7. Bikmukhametov, I.; Beladi, H.; Wang, J.; Tari, V.; Rollett, A.D.; Hodgson, P.D.; Timokhina, I. Interface characteristics and precipitation during the austenite-to-ferrite transformation of a Ti-Mo microalloyed steel. J. Alloys Compd. 2022, 893, e162224. [CrossRef]

8. Ioannidou, C.; Arechabaleta, Z.; Navarro-López, A.; Rijkenberg, A.; Dalgliesh, R.M.; Kölling, S.; Bliznuk, V.; Pappas, C.; Sietsma, J.; van Well, A.A.; et al. Interaction of precipitation with austenite-to-ferrite phase transformation in vanadium micro-alloyed steels. Acta Mater. 2019, 181, 10-24. [CrossRef]

9. Zhao, H.; Palmiere, E.J. Effect of austenite grain size on acicular ferrite transformation in a HSLA steel. Mater. Charact. 2018, 145, 479-489. [CrossRef]

10. Moon, J.; Lee, T.-H.; Kim, S.-D.; Lee, C.-H.; Jang, J.H.; Shin, J.-H.; Lee, J.o.; Lee, B.H.; Suh, D.-W. Isothermal transformation of austenite to ferrite and precipitation behavior in $9 \mathrm{Cr}-1.5 \mathrm{Mo}-1.25 \mathrm{Co}-0.1 \mathrm{C}-\mathrm{VNb}$ heat-resistant steel. Mater. Charact. 2020, 170 , e110677. [CrossRef]

11. Polatidis, E.; Haidemenopoulos, G.N.; Krizan, D.; Aravas, N.; Panzner, T.; Šmíd, M.; Papadioti, I.; Casati, N.; van Petegem, S.; van Swygenhoven, $\mathrm{H}$. The effect of stress triaxiality on the phase transformation in transformation induced plasticity steels: Experimental investigation and modelling the transformation kinetics. Mater. Sci. Eng. A Struct. 2021, 800, e140321. [CrossRef]

12. Liu, Y.C.; Sommer, F.; Mittemeijer, E.J. Austenite-ferrite transformation kinetics under uniaxial compressive stress in Fe-2.96at.\% Ni alloy. Acta Mater. 2009, 57, 2858-2868. [CrossRef]

13. Li, Z.D.; Yang, Z.G.; Zhang, C.; Liu, Z.Q. Influence of austenite deformation on ferrite growth in a Fe-C-Mn alloy. Mater. Sci. Eng. A Struct. 2010, 527, 4406-4411. [CrossRef]

14. Larsson, H. A model for 1D multiphase moving phase boundary simulations under local equilibrium conditions. Calphad 2014, 47, 1-8. [CrossRef]

15. Lee, J.S.; Suh, D.-W.; Koo, Y.M.; Kim, S.G. Numerical modelling of moving interfaces under local equilibrium conditions. Calphad 2017, 59, 164-170. [CrossRef]

16. Bos, C.; Mecozzi, M.G.; Sietsma, J. A microstructure model for recrystallisation and phase transformation during the dual-phase steel annealing cycle. Comp. Mater. Sci. 2010, 48, 692-699. [CrossRef]

17. Zhang, L.; Zhang, C.B.; Wang, Y.M.; Wang, S.Q.; Ye, H.Q. A cellular automaton investigation of the transformation from austenite to ferrite during continuous cooling. Acta Mater. 2003, 51, 5519-5527. [CrossRef]

18. Fang, H.; Zwaag, S.; Dijk, N.H. A novel 3D mixed-mode multigrain model with efficient implementation of solute drag applied to austenite-ferrite phase transformations in Fe-C-Mn alloys. Acta Mater. 2021, 212, e116897. [CrossRef]

19. Pernach, M.; Pietrzyk, M. Numerical solution of the diffusion equation with moving boundary applied to modelling of the austenite-ferrite phase transformation. Com. Mater. Sci. 2008, 44, 783-791. [CrossRef]

20. Saito, Y.; Matsuzaki, A.; Shiga, C. Computer simulation of microstructural evolution in thermo-mechanical processing of steel plates. ISIJ Int. 1992, 32, 414-422. [CrossRef]

21. Moelans, N.; Blanpain, B.; Wollants, P. An introduction to phase-field modeling of microstructure evolution. Calphad 2008, 32, 268-294. [CrossRef] 
22. Huang, C.J.; Browne, D.J.; McFadden, S. A phase-field simulation of austenite to ferrite transformation kinetics in low carbon steels. Acta Mater. 2006, 54, 11-21. [CrossRef]

23. Bhattacharya, A.; Mondal, K.; Upadhyay, C.; Sangal, S. A phase-field investigation of the effect of grain-boundary diffusion on austenite to ferrite transformation. Comp. Mater. Sci. 2020, 173, e109428. [CrossRef]

24. Palumbo, M.; Battezzati, L. Thermodynamics and kinetics of metallic amorphous phases in the framework of the CALPHAD approach. Calphad 2008, 32, 295-314. [CrossRef]

25. McAnulty, M.J.; Potirniche, G.P.; Tokuhiro, A. The application of an internal state variable model to the viscoplastic behavior of irradiated ASTM 304L stainless steel. Nucl. Eng. Des. 2012, 250, 1-7. [CrossRef]

26. Roucoules, C.; Pietrzyk, M.; Hodgson, P.D. Analysis of work hardening and recrystallization during the hot working of steel using a statistically based internal variable model. Mater. Sci. Eng. A Struct. 2003, 339, 1-9. [CrossRef]

27. An, D.; Pan, S.; Ren, Q.; Li, Q.; Krakauer, B.W.; Zhu, M. A Gibbs energy balance model for the isothermal ferrite-to-austenite transformation. Scr. Mater. 2020, 178, 207-210. [CrossRef]

28. Kalantari, A.-R.; Zarei-Hanzaki, A.; Abedi, H.R.; Park, S.-J.; Park, J.Y. Bi-directional ferrite to austenite transformation through warm temperature deformation of a ferrite-based low density steel. Mater. Sci. Eng. A Struct. 2021, 821, e141596. [CrossRef]

29. Ollat, M.; Militzer, M.; Massardier, V.; Fabregue, D.; Buscarlet, E.; Keovilay, F.; Perez, M. Mixed-mode model for ferrite-to-austenite phase transformation in dual-phase steel. Comput. Mater. Sci. 2018, 149, 282-290. [CrossRef]

30. Chen, H.; Zwaag, S. A general mixed-mode model for the austenite-to-ferrite transformation kinetics in Fe-C-M alloys. Acta Mater. 2014, 72, 1-12. [CrossRef]

31. Lee, J.L.; Bhadeshia, H.K.D.H. A methodology for the prediction of time temperature-transformation diagrams. Mater. Sci. Eng. A 1993, 171, 223-230. [CrossRef]

32. Liu, Z.; Wang, G.; Zhang, Q. On the transformation kinetics of work-hardened austenite $(\gamma) \rightarrow$ pro-eutectoid ferrite $(\alpha)$ of C-Mn steels. J. Mater. Process. Technol. 1994, 44, 75-80. [CrossRef]

33. Farahani, H.; Zurob, H.; Hutchinson, C.R.; van der Zwaag, S. Effect of $C$ and $N$ and their absence on the kinetics of austenite-ferrite phase transformations in Fe-0.5Mn alloy. Acta Mater. 2018, 150, 224-235. [CrossRef]

34. Song, S.J.; Che, W.K.; Zhang, J.B.; Huang, L.K.; Duan, S.Y.; Liu, F. Kinetics and microstructural modeling of isothermal austeniteto-ferrite transformation in Fe-C-Mn-Si steels. J. Mater. Sci. Technol. 2019, 35, 1753-1766. [CrossRef]

35. Liu, Y.C.; Sommer, F.; Mittemeijer, E.J. Kinetics of the abnormal austenite-ferrite transformation behaviour in substitutional Fe-based alloys. Acta Mater. 2004, 52, 2549-2560. [CrossRef]

36. Bao, W.P.; Pan, R.Q.; Wang, R.F.; Ren, X.P. Continuous Cooling Transformation Curve of Overcooling Austenite for 20MnSi Steel. Hot Work. Technol. 2009, 18, 34-36.

37. Zhao, H.Z.; Liu, X.H.; Wang, G.D. Progress in modeling of phase transformation kinetics. J. Iron. Steel Res. Int. 2006, 13, 68-73. [CrossRef]

38. Campell, P.C.; Hawbolt, E.B.; Brimacombe, J.K. Microstructural engineering applied to the controlled cooling of steel wire rod: Part II. microstructural evolution and mechanical properties correlations. Metall. Trans. A 1991, 22, 2779-2790. [CrossRef]

39. Umenoto, M.; Nishioka, N. Prediction of hardenability from isothermal transformation diagrams. Trans. ISIJ 1982, 22, 629-636. [CrossRef]

40. Murugaiyan, A.; Podder, A.S.; Pandit, A.; Chandra, S.; Bhattacharjee, D.; Ray, R.K. Phase transformation in two C-Mn-Si-Cr phase dual phase steels. ISIJ Int. 2006, 46, 1489-1494. [CrossRef]

41. Donnay, B.; Herman, J.C.; Leroy, V.; Crm, B.; Lotter, U.; Grossterlinden, R.; Pircher, H.; Stahl, T. Microstructure evolution of C-Mn steel in the hot deformation process. In Proceedings of the 2nd International Conference on Modeling of Metal Rolling Processes, London, UK; 1996; pp. 23-35.

42. Lee, J.K. Prediction of $\gamma / \alpha$ transformation during continuous cooling of steel. In Proceedings of the 41st Mechanical Working and Steel Processing Conference Proceeding, Baltimore, MD, USA, 24-27 October 1999; Volume 37, pp. $975-981$.

43. Kim, J.K.; Kim, J.H.; Suh, D.W. Partially-recrystallized ferrite grains and multiple plasticity enhancing mechanisms in a medium Mn steel. Mater. Charact. 2019, 155, e109812. [CrossRef]

44. Yilmaz, H.; Williams, C.J.; Derby, B. Size effects on strength and plasticity of ferrite and austenite pillars in a duplex stainless steel. Mater. Sci. Eng. A Struct. 2020, 793, e139883. [CrossRef]

45. Imandoust, A.; Zarei-Hanzaki, A.; Heshmati-Manesh, S.; Moemeni, S.; Changizian, P. Effects of ferrite volume fraction on the tensile deformation characteristics of dual phase twinning induced plasticity steel. Mater. Des. 2014, 53, 99-105. [CrossRef] 